\title{
Nurses' Knowledge, Attitudes and Practice in Anti-Smoking Campaigns in Morocco
}

\author{
Majdouline Obtel1,2*, Katia Slama1, Naima Abda1, Nabil Tachfouti1, Mohamed Berraho', \\ Inaam Obtel ${ }^{1}$, Simone Mathoulin Pelissier ${ }^{3,4,5}$, Chakib Nejjari ${ }^{1}$ \\ ${ }^{1}$ Department of Epidemiology, Clinical Research and Public Health, Fez, Morocco \\ ${ }^{2}$ Directorate of Epidemiology and Diseases Control, Ministry of Health, Rabat, Morocco \\ ${ }^{3}$ Equipe "Epidémiologie des Cancers", INSERM 897, ISPED, Bordeaux, France \\ ${ }^{4}$ Université Victor Segalen, ISPED, INSERM CIC-EC7, Bordeaux, France \\ ${ }^{5}$ Unité de Recherche Epidémiologique et Clinique, Institut Bergonié, CRLCC, Bordeaux, France \\ Email: majdobtel7@yahoo.fr
}

Received 20 April 2014; revised 28 May 2014; accepted 5 June 2014

Copyright (C) 2014 by authors and OALib.

This work is licensed under the Creative Commons Attribution International License (CC BY). http://creativecommons.org/licenses/by/4.0/

(c) (i) Open Access

\section{Abstract}

Background: Health professionals have a major role in tobacco control efforts, as they are generally considered to be role models in communities. Nurses in particular, being usually the largest group of health care workers, are ideally placed to promote smoking cessation. The aim of this study was to assess tobacco use of nurses and their knowledge, attitudes and practice on tobacco control in the region of Fez in Morocco. Methods: A cross-sectional study focused on public practicing nurses, over a period of 2 months in 2009, in the university hospital and in the primary health care centres of the region of Fez in Morocco. Results: In total, 120 nurses participated in the study. Mean age was 42.2 years (11.8 years SD; from 22 to 64 years). There were $13.4 \%$ smokers, among whom $\mathbf{9 . 2 \%}$ daily smokers. Men considered themselves better trained in tobacco cessation activities than women $(84.8 \%$ vs. $60.0 \%, p=0.02)$. Women considered the role of nurses in tobacco prevention as important, and were more convinced of the anti-tobacco effectiveness actions $(\mathbf{9 0 . 0 \%}$ vs. $52.1 \%$, p < 0.001). No-smokers were significantly more convinced in general in the effectiveness of anti-tobacco measures, with a significant difference on interdicts to smoke in public places $\mathbf{2 0 . 0 \%} \mathrm{vs}$. $3.1 \%, p=0.03$ ). Conclusion: Nurses in the region of Fez in Morocco would be motivated to contribute to tobacco control programs if they had appropriate resources. Their interest offers an important opportunity to strengthen their knowledge, attitudes and practices as smoking cessation supporters.

\section{Keywords}

Paramedical Professional, Behaviors, Tobacco Control, Tobacco Prevention

\footnotetext{
${ }^{*}$ Corresponding author.
}

How to cite this paper: Obtel, M., Slama, K., Abda, N., Tachfouti, N., Berraho, M., Obtel, I., Pelissier, S.M. and Nejjari, C. (2014) Nurses' Knowledge, Attitudes and Practice in Anti-Smoking Campaigns in Morocco. Open Access Library Journal, 1: e549. http://dx.doi.org/10.4236/oalib.1100549 


\section{Introduction}

As knowledge on tobacco-related diseases increases, tobacco continues to kill up to half of its users, with more than $80 \%$ of the world's one billion smokers living in low or middle-income countries [1]. In Morocco, where $31.5 \%$ of males and $3.1 \%$ of females are current smokers [2], the government has strengthened in July 2008 the law against smoking in public places, sale of tobacco to minors, and advertising of tobacco products, but its implementation remains highly ineffective [3]. However, there are many ways to tackle the fight against the tobacco epidemic, in particular through health professionals, who can focus both on preventing tobacco use initiation and promoting tobacco use cessation. Health professionals have a major role in tobacco control efforts, as they are generally considered to be role models in communities. Nurses in particular, being usually the largest group of health care workers, are ideally placed to promote smoking cessation, and can encourage others to not begin to use tobacco products [4] [5]. Nursing-delivered smoking cessation interventions have proved to be effective [6]. However, many studies have shown that nurses are insufficiently trained and lack sufficient resources to efficiently counsel patients about tobacco use [7]. To our knowledge, no study exploring smoking behaviour, knowledge and attitudes among nurses has ever been conducted in Morocco. The aim of this study was to assess tobacco use of nurses, their attitudes, knowledge and practices on tobacco control in the region of Fez in Morocco.

\section{Methods}

The current research focused on public practicing nurses in the region of Fez in Morocco, over a period of 2 months starting in January 2009. This is a cross-sectional study of randomly selected nurses. Only urban and rural primary clinical health centres and services of the university hospital (HASSAN II hospital) integrated into the university program to meet nurse's trainees at the time of this research were randomly selected to be included in the study.

Analyses were based on a sample of nurses, practicing mainly in eight services (pneumology, neurology, internal medicine, ophthalmology, oto-rhino-laryngology, reanimation, surgery and emergencies) in the university hospital and in twelve primary clinical health centres (four rural centers and eight urban centres) of Fez. To distribute the questionnaire, three entrained nurses were meted by the nurses' chief of each centre, who was informed about the aim of the study. Only present and available nurses at the moment of investigators' visit received the questionnaire and were included in this study. Informed consent was obtained. Nurses were informed that participation was voluntary and that personal identifying information was not being requested.

Self-administered anonymous questionnaires were applied. In addition to socio-demographic characteristics (age, sex, area of work, date and location of obtained diploma), the questionnaire consisted of 22 items about smoking knowledge, attitudes and practices and intention to participate in tobacco control. The questionnaire included also questions about their smoking status, duration of smoking and daily cigarette consumption. Smoking habit was defined according to the International Union Against Tuberculosis and Lung Diseases guide [8]. Respondents were defined as current smokers or smokers (daily and occasional smokers) if they were smoking at the time of the survey and had smoked more than 100 cigarettes in their lifetime; defined as former smokers if they had smoked more than 100 cigarettes in their lifetime, but stopped smoking during more than 3 months at the time of the survey; and defined as never smokers if they had never smoked or had smoked less than 100 cigarettes in their lifetime [2].

Smoking knowledge was assessed through questions on tobacco-related diseases, using a scale of 4 scores to evaluate how much the nurses linked the diseases to tobacco (no link $=1$; strong link $=4$ ). Some aspects of the questionnaire considered knowledge on anti-tobacco legislation in Morocco. Information on attitudes and practices was gathered through views of nurses as role models and importance of this role in tobacco-cessation intervention; smoking status and exposure to second-hand smoking; actual training received to help patients quit smoking; intention to participate and major obstacles in tobacco control activities and demand for more instruction and attitudes when faced to smoking patients. 
The data collected were entered and analyzed with SPSS version 17.0. Descriptive statistics and frequencies were computed for each variable in the questionnaire. Univariate analysis was performed using classic tests (Anova, Student and Chi-square). We regrouped the never smokers and the former smokers into no smoker variable to complete the comparison analysis.

\section{Results}

A total of 120 subjects were included in the study. The overall survey response rate was $88.2 \%$.

\subsection{Socio-Demographic Characteristics and Tobacco Status}

As seen in Table 1, there were a majority of women (56.7\%) in this study. Mean age of the participants was 42.2 years (11.8 years of standard deviation, ranging from 22 to 64 years). Approximately half of the nurses (47.5\%) had more than 25 years of professional experience. There were 13.4\% current smokers, among whom $9.2 \%$ daily smokers. Those who weren't smokers were in majority exposed to second-hand smoke through family or work (61.5\% and 58.2\% respectively).

Table 1. Socio-demographic characteristics and tobacco status of participants.

\begin{tabular}{|c|c|}
\hline Variable & $\mathrm{N}(\%)$ \\
\hline \multicolumn{2}{|l|}{ Gender } \\
\hline Female & $68(56.7)$ \\
\hline Male & $52(43.3)$ \\
\hline \multicolumn{2}{|l|}{ Age group (in years) } \\
\hline$<40$ & $42(35.0)$ \\
\hline $40-49$ & $36(30.0)$ \\
\hline$\geq 50$ & $42(35.0)$ \\
\hline \multicolumn{2}{|l|}{ professional experience (in years) } \\
\hline$\leq 10$ & $37(30.8)$ \\
\hline $11-25$ & $26(21.7)$ \\
\hline$>25$ & $57(47.5)$ \\
\hline \multicolumn{2}{|l|}{ Area of exercise } \\
\hline Urban & $109(90.8)$ \\
\hline Rural & $11(9.2)$ \\
\hline \multicolumn{2}{|l|}{ Tobacco status } \\
\hline Daily smoker & $11(9.2)$ \\
\hline Occasional smoker & $5(4.2)$ \\
\hline Former smoker & $9(7.5)$ \\
\hline Never-smoker & $95(79.2)$ \\
\hline \multicolumn{2}{|l|}{ Never smokers and former smokers } \\
\hline Exposure to smoke in family & $67(61.5)$ \\
\hline No exposure & $42(38.5)$ \\
\hline \multicolumn{2}{|c|}{ Never smokers and former smokers } \\
\hline Exposure to smoke at work & $64(58.2)$ \\
\hline No exposure & $46(41.8)$ \\
\hline \multicolumn{2}{|l|}{ Tobacco status } \\
\hline Current Smoker Female & $2(2.9)$ \\
\hline Male & 14 (26.9) \\
\hline
\end{tabular}


There were no significant differences between tobacco status and professional experience. More women were in the more experienced group $(55.9 \%$ vs. $47.6 \%, \mathrm{p}=0.04)$ and more men were current smokers $(26.9 \%$ vs. $2.9 \%, \mathrm{p}<0.001)$. These results are not showed in tables.

\subsection{Knowledge on Tobacco-Related Diseases}

Table 2 presents the association between knowledge on tobacco-related diseases and gender, professional experience and tobacco status.

Gender: in general, males were more aware of the link between tobacco and the different diseases, with significant differences regarding bladder cancer (mean $=2.28$ for males vs. $1.73, \mathrm{p}=0.02$ ) and arteritis (mean $=$ 3.14 for males vs. 2.78, $\mathrm{p}=0.05$ ).

Experience: More professionally experienced nurses were significantly more convinced in the link between tobacco and lung cancer (mean $=3.97$ for less experienced nurses vs. $3.79, \mathrm{p}=0.04$ ). . No other significant differences were found between more and less experienced nurses.

Tobacco status: there were no significant differences in knowledge according to tobacco status.

\subsection{Training and Attitudes}

More than two thirds of the nurses (71.0\%) had received some training in tobacco cessation during their studies, and 1 in 4 (24.1\%) had received information after their studies. In total, approximately two thirds (69.5\%) of the nurses felt competent to help smokers quit. Table 3 shows differences in training and attitudes in regard to gender, professional experience or tobacco status.

Gender: men in general considered themselves better trained in tobacco cessation activities than women, with a significant difference in participation to conferences $(84.8 \%$ vs. $60.0 \%, \mathrm{p}=0.02)$. More females considered the role of nurses in tobacco prevention as important (for women the role of nurses in tobacco prevention was more important than for men but this difference was not significant), and they were more convinced of the effectiveness of anti-tobacco actions, particularly increasing the price of tobacco $(90.0 \%$ vs. $52.1 \%, \mathrm{p}<0.001)$.

Experience: nurses with more than 25 years of professional experience considered they were trained to help patients to quit smoking while younger nurses felt that they had been less trained $(42.0 \%$ vs. $17.5 \%, p=0.005)$. Also, there was a significant difference in participation in preventive actions (54.9\% over 25 years experience vs. $32.8 \%, \mathrm{p}=0.02$ ). Other significant differences were found in their opinion on anti-tobacco measures, more experienced nurses being more convinced of the effectiveness of these measures.

Tobacco status: No-smokers (never smokers and former smokers) were significantly more to consider the role of nurses as important in tobacco prevention $(88.3 \%$ vs. $68.8 \%, \mathrm{p}=0.04)$. They were also more convinced in general in the effectiveness of anti-tobacco measures, with a significant difference on bans to smoke in public places $(20.0 \%$ vs. $3.1 \%, \mathrm{p}=0.03)$. There were no significant differences in training according to tobacco status.

Table 2. Knowledge on tobacco-related diseases according to gender, professional experience and tobacco status.

\begin{tabular}{|c|c|c|c|c|c|c|c|c|c|}
\hline \multirow{2}{*}{ Variable } & \multicolumn{2}{|c|}{$\begin{array}{c}\text { Gender } \\
\text { Mean of score (SD) }\end{array}$} & \multirow{2}{*}{$\mathrm{p}$} & \multicolumn{2}{|c|}{$\begin{array}{l}\text { Experience in years } \\
\text { Mean of score (SD) }\end{array}$} & \multirow{2}{*}{$\mathrm{p}$} & \multicolumn{2}{|c|}{$\begin{array}{c}\text { Tobacco status } \\
\text { Mean of score (SD) }\end{array}$} & \multirow{2}{*}{$\mathrm{p}$} \\
\hline & Woman & Man & & $\leq 25$ & $>25$ & & Smoker & No smoker & \\
\hline Link tobacco to lung cancer & $3.87(0.49)$ & $3.90(0.45)$ & 0.68 & $3.97(0.18)$ & $3.79(0.65)$ & 0.04 & $3.75(0.77)$ & $3.9(0.41)$ & 0.23 \\
\hline Link tobacco to chronic bronchitis & $3.72(0.68)$ & $3.75(0.59)$ & 0.83 & $3.72(0.61)$ & $3.74(0.68)$ & 0.87 & $3.67(0.82)$ & $3.74(0.61)$ & 0.68 \\
\hline Link tobacco to mouth cancer & $3.45(0.85)$ & $3.38(0.90)$ & 0.68 & $3.31(0.96)$ & $3.54(0.75)$ & 0.17 & $3.40(0.99)$ & $3.42(0.86)$ & 0.93 \\
\hline Link tobacco to larynx cancer & $3.52(0.73)$ & $3.62(0.77)$ & 0.51 & $3.61(0.74)$ & $3.52(0.76)$ & 0.52 & $3.56(0.81)$ & $3.56(0.74)$ & 1.0 \\
\hline Link tobacco to coronaropathy & $3.30(0.84)$ & $3.45(0.75)$ & 0.35 & $3.50(0.71)$ & $3.21(0.87)$ & 0.06 & $3.38(0.87)$ & $3.36(0.80)$ & 0.93 \\
\hline Link tobacco to arteritis & $2.78(1.01)$ & $3.14(0.91)$ & 0.05 & $3.03(0.98)$ & $2.83(0.97)$ & 0.29 & $2.93(0.92)$ & 2.95 (0.99) & 0.95 \\
\hline Link tobacco to stroke & $3.08(0.92)$ & $2.92(0.87)$ & 0.34 & $2.95(0.92)$ & $3.08(0.87)$ & 0.45 & $2.75(0.86)$ & $3.05(0.86)$ & 0.21 \\
\hline Link tobacco to bladder cancer & $1.73(1.07)$ & $2.28(1.21)$ & 0.02 & $2,00(1.20)$ & $1.94(1.13)$ & 0.79 & $2.47(1.30)$ & $1.89(1.12)$ & 0.08 \\
\hline
\end{tabular}

Scale of 4 scores to evaluate how much the nurses linked the diseases to tobacco (no link = 1; strong link =4). 
Table 3. Training and attitudes in tobacco cessation activities according to gender, professional experience and smoking status.

\begin{tabular}{|c|c|c|c|c|c|c|c|c|c|}
\hline \multirow{2}{*}{ Variable } & \multicolumn{2}{|c|}{$\begin{array}{l}\text { Gender } \\
\text { N (\%) }\end{array}$} & \multirow{2}{*}{$\mathrm{p}$} & \multicolumn{2}{|c|}{$\begin{array}{l}\text { Experience in years } \\
\mathrm{N}(\%)\end{array}$} & \multirow{2}{*}{$\mathrm{p}$} & \multicolumn{2}{|c|}{$\begin{array}{l}\text { Tobacco status } \\
\text { N (\%) }\end{array}$} & \multirow{2}{*}{$\mathrm{p}$} \\
\hline & Woman & Man & & $\leq 25$ & $>25$ & & Smoker & No smoker* & \\
\hline Tobacco cessation training during studies (Yes) & $15(24.6)$ & $16(34.8)$ & 0.25 & $10(17.5)$ & $21(42.0)$ & 0.005 & $5(33.3)$ & $26(28.3)$ & 0.7 \\
\hline Have participated in conferences (Yes) & $27(60.0)$ & $28(84.8)$ & 0.02 & $33(78.6)$ & $22(61.1)$ & 0.09 & $9(75.0)$ & $46(69.7)$ & 1.0 \\
\hline Participate in preventive actions (Yes) & $26(42.6)$ & $21(43.7)$ & 0.91 & $19(32.8)$ & 28 (54.9) & 0.02 & 3 (21.4) & 44 (46.3) & 0.09 \\
\hline $\begin{array}{l}\text { Importance of nurse's role } \\
\text { (Very important) }\end{array}$ & 59 (88.1) & 43 (82.7) & 0.41 & 50 (80.6) & 52 (91.2) & 0.1 & 11 (68.8) & 91 (88.3) & 0.04 \\
\hline $\begin{array}{l}\text { Agree with effectiveness of no } \\
\text { smoking in public spaces (Yes) }\end{array}$ & $63(98.4)$ & 43 (89.6) & 0.08 & 53 (94.6) & 53 (94.6) & 1.0 & $3(20.0)$ & $3(3.1)$ & 0.03 \\
\hline $\begin{array}{l}\text { Agree with effectiveness of higher } \\
\text { cost of tobacco (Yes) }\end{array}$ & $54(90.0)$ & $25(52.1)$ & $<10^{-3}$ & 35 (64.8) & 44 (81.5) & 0.05 & 8 (53.3) & 71 (76.3) & 0.06 \\
\hline $\begin{array}{l}\text { Agree with effectiveness of } \\
\text { advertisement on tobacco packs (Yes) }\end{array}$ & 52 (88.1) & 34 (75.6) & 0.09 & $37(74.0)$ & 49 (90.7) & 0.02 & $10(71.4)$ & $76(84.4)$ & 0.26 \\
\hline
\end{tabular}

*No smokers: never smokers and former smokers.

\subsection{Tobacco Prevention Practices}

Three nurses in four asked their patients about their smoking status and a little more than half (54.1\%) put the information on the medial record. Most nurses (86.6\%) advised their smoking patients to quit and 61.1\% proposed to help them. Table 4 shows the association between tobacco prevention practices and gender, professional experience and tobacco status.

Gender: there were no significant differences in practices.

Experience: there were a significant difference in motivating patients to quit smoking, younger nurses being more apt to motivate their patients $(85.4 \%$ vs. $64.4 \%, \mathrm{p}=0.01)$.

Tobacco status: significant differences were found regarding advices to quit smoking when treating a smoker and proposing help to quit, non-smokers being more likely to act (89.8\% vs. 64.3\%, $\mathrm{p}=0.01$ and $65.8 \%$ vs. $35.7 \%, \mathrm{p}=0.03$ respectively).

\subsection{Major Obstacles in Tobacco Cessation Practices}

The most cited obstacles in tobacco cessation practices were lack of motivation of patients (85.7\%) and lack of resources (73.1\%). As seen in Table 5, nurses with more professional experience were significantly less motivated and interested in tobacco cessation practices $(57.1 \%$ vs. 36.5\%, $p=0.04$ and $43.5 \%$ vs. $16.7 \%, p=0.04$ respectively). There were no significant differences between obstacles in tobacco cessation practices and gender or tobacco status.

\section{Discussion}

The current study is among the very few studies in Morocco to assess the healthcare professionals in regard to smoking and perception of their role in tobacco cessation. Previous data on behaviour of hospital staff with regard to smoking in 1999 in Casablanca’s hospitals assessed smoking and knowledge, attitudes, practices of paramedical staff, doctors, laboratory staff and administrators [9].

Nurses in low- and middle-income countries have an increasing role in the management of chronic diseases [10], such as tobacco-related disease (cancer, chronic respiratory diseases and cardiovascular diseases) [11]. Smoking rates were $2.9 \%$ in women and $26.9 \%$ in men, similar to the last known Moroccan rates evaluated from a national survey [2]. A majority of the nurses (71.0\%) had received training on tobacco cessation during their studies though only one in four (24.2\%) had any follow-up information once they finished their studies. Accordingly, approximately the same percentage of nurses felt enough or very competent to help their patients quit smoking, and $75.4 \%$ asked their patients about their smoking status. This very minimal act of screening patients for tobacco use has demonstrated effectiveness in helping people stop smoking [12] and in this context where 
Table 4. Practices according to gender, professional experience and tobacco status.

\begin{tabular}{|c|c|c|c|c|c|c|c|c|c|}
\hline \multirow{2}{*}{ Variable } & \multicolumn{2}{|c|}{ Gender N (\%) } & \multirow{2}{*}{$\mathrm{p}$} & \multicolumn{2}{|c|}{ Experience in years $\mathrm{N}(\%)$} & \multirow{2}{*}{$p$} & \multicolumn{2}{|c|}{ Tobacco status N (\%) } & \multirow{2}{*}{$\mathrm{p}$} \\
\hline & Woman & Man & & $\leq 25$ & $>25$ & & Smoker & No smoker & \\
\hline Ask about tobacco when treating patient (Yes) & 49 (73.1) & $40(78.4)$ & 0.51 & 45 (73.8) & $44(77.2)$ & 0.67 & $9(60.0)$ & $80(77.7)$ & 0.14 \\
\hline Inform medical record on tobacco status (Yes) & $23(53.5)$ & $23(54.8)$ & 0.91 & $27(54.0)$ & $19(54.3)$ & 0.98 & $9(64.3)$ & $37(52.1)$ & 0.40 \\
\hline Advice quitting if patient smokes (Yes) & $54(85.7)$ & $43(87.8)$ & 0.75 & $53(88.3)$ & $44(84.6)$ & 0.56 & 9 (64.3) & 88 (89.8) & 0.01 \\
\hline Motivate patients to quit smoking (Yes) & 39 (73.6) & $37(78.7)$ & 0.55 & $47(85.4)$ & $29(64.4)$ & 0.01 & $11(73.3)$ & 65 (76.5) & 0.79 \\
\hline Propose treatment to quit smoking (Yes) & 30 (62.5) & 25 (59.5) & 0.77 & $25(54.3)$ & $30(68.2)$ & 0.18 & $5(35.7)$ & $50(65.8)$ & 0.03 \\
\hline
\end{tabular}

Table 5. Major obstacles in tobacco cessation practices according to gender, professional experience and tobacco status.

\begin{tabular}{|c|c|c|c|c|c|c|c|c|c|}
\hline \multirow{2}{*}{ Variable } & \multicolumn{2}{|c|}{$\begin{array}{l}\text { Gender } \\
\mathrm{N}(\%)\end{array}$} & \multirow{2}{*}{$\mathrm{p}$} & \multicolumn{2}{|c|}{ Experience in years $\mathrm{N}(\%)$} & \multirow{2}{*}{$\mathrm{p}$} & \multicolumn{2}{|c|}{$\begin{array}{c}\text { Tobacco status } \\
\text { N (\%) }\end{array}$} & \multirow{2}{*}{$\mathrm{p}$} \\
\hline & Woman & Man & & $\leq 25$ & $>25$ & & smoker & Non smoker & \\
\hline Lack of training (Yes) & $34(63.3)$ & $26(59.1)$ & 0.70 & $32(62.8)$ & $28(59.6)$ & 0.75 & $11(73.3)$ & $49(59.0)$ & 0.39 \\
\hline Lack of time (Yes) & $32(61.5)$ & $26(59.1)$ & 0.81 & $26(52.0)$ & $32(69.6)$ & 0.08 & $6(42.9)$ & $52(63.4)$ & 0.15 \\
\hline Lack of motivation (Yes) & $30(54.5)$ & $17(37.0)$ & 0.08 & 19 (36.5) & $28(57.1)$ & 0.04 & $7(43.7)$ & $40(47.1)$ & 0.81 \\
\hline Lack of interest (Yes) & $16(31.4)$ & $12(27.9)$ & 0.71 & $8(16.7)$ & $20(43.5)$ & 0.04 & $3(20)$ & $25(31.7)$ & 0.54 \\
\hline
\end{tabular}

most nurses (73.1\%) cited lack of resources as an obstacle in tobacco cessation practices, an attempt to achieve the goal of $100 \%$ nurses performing the minimal advice is essential as it remains an extremely cost-effective intervention [13]. Also, a review of literature showed that the effects of training on process outcomes increased if prompts and reminders were used [14], suggesting the need to encourage Moroccan nurses to follow post degree training courses to effectively implement the tobacco cessation interventions.

The US National Cancer Institute has recommended the use of 5 A's for brief tobacco interventions (Ask, Assess, Advice, Assist, Arrange) [15]. Our study shows that while most nurses ask (75.4\%) and advice (86.6\%), the rates fall to 6 in 10 when asked about assisting. The same attitudes were noted in an Italian study of general practitioners [16], and can be explained in the present study by the high percentage of nurses (85.7\%) who believe that patients are not motivated. Differences according to professional experience were found in training and attitudes. More experienced nurses, having worked longer, were more prone to have assisted in post-degree trainings. Nevertheless, more experienced nurses were less convinced by the link between pulmonary cancer and tobacco than younger nurses. This must be explained by the fact that, the former nurses were less trained about tobacco and risk factors than the youngest ones. However, they linked tobacco to pulmonary cancer at a mean of score 3.8, a high grade demonstrating globally the acceptance of tobacco as the leading cause to pulmonary cancer for all nurses, similarly to an Australian study showing that knowledge about the health effects of smoking was high among nurses [17]. Also, more experienced nurses appeared less motivated and interested in tobacco cessation interventions. This is consistent with a literature review showing that nurses aged under 30 were more motivated than older nurses [18]. In Morocco, where working conditions can be difficult, it is very important to re-motivate older and more experienced nurses.

Finally, when comparing smokers to no-smokers, it was interesting to find differences in practices. Smokers were less likely to consider the role of nurses in tobacco cessation activities or to motivate and help patients quit. Similar results were found in numerous studies. In Nepal, current tobacco users among health professionals were less likely to always ask ( $p<0.001)$ and advise $(p<0.001)$ on tobacco use compared to nonusers [19]. On a different level, Serbian nurses who smoked were significantly less likely to believe that their counseling about smoking could be effective. They also felt significantly less well prepared to assist patients to quit smoking [20].

Such results should encourage nurses' faculty leaders to implement tobacco cessation programs among their nursing students. An American study exploring differences in smokers' perceptions of the effectiveness of cessation media messages showed that smokers who had less desire to quit or had not tried quitting in the past 12 
months responded significantly less favorably to all types of cessation ads [21]. If nurses who smoke respond differently to anti-tobacco campaigns than no smokers, it would explain why they feel less incline in motivating their patients to quit smoking. Getting nurses to quit would highly enhance their participation in anti-tobacco strategies and promote healthy behaviors among the community. Nurses' major obstacles in tobacco cessation activities were lack of motivation of patients (85.7\%) and lack of resources (73.1\%). Similar barriers are often cited in various settings: a study in the United Arab Emirates where the main obstacle for nurses to perform tobacco cessation interventions was that patients may not appreciate it (90.6\%) [22]. In Hong Kong, the most common barriers for nurses included unmotivated patients (84.5\%), lack of time (68.9\%) and lack of resources (64\%) [23]. Therefore, as in many countries, it is necessary to raise people's awareness on the dangers related to smoking, by effective measures such as picture warnings [1].

This Moroccan study is an exploratory one, given several limitations. It was carried out in very few rural centers, because in the majority of rural areas, we have only one nurse per centre. Therefore, due to the exploratory nature of the survey on a convenient sample of nurses, our results can only provide a snapshot on knowledge, attitudes and practices of nurses in Fez. However, our study is expected to set a benchmark for further studies about medical professionals' role and training nursing students in tobacco control. Also, participation in our survey was voluntary and we cannot rule out some selection bias. However, we obtained $88.2 \%$ response rate, and our sample was representative of nurses in the region of Fez, knowing there is inequality of repartition of human resources in health care between rural and urban areas [24].

\section{Conclusion}

Our study has stressed out many observations and facts. Nurses in the region of Fez, Morocco would be motivated to contribute to tobacco control programs if they had appropriate resources. Their interest offers an important opportunity to strengthen their knowledge, attitudes and practices as smoking cessation supporters.

\section{Acknowledgements}

The authors would like to thank all nurses who participated in this study.

\section{Competing Interests}

None.

\section{References}

[1] WHO Fact Sheet No. 339 (2011) http://www.who.int/mediacentre/factsheets/fs339/en/index.html

[2] Nejjari, C., Benjelloun, M.C., Berraho, M., et al. (2009) Prevalence and Demographic Factors of Smoking in Morocco. International Journal of Public Health, 54, 447-451. http://dx.doi.org/10.1007/s00038-009-0082-2

[3] El Arif H. Loi antitabac: un texte pour la forme? L’économiste, Edition No. 3233, 2010. http://www.leconomiste.com/article/loi-antitabac-un-texte-pour-la-forme

[4] Wong, G., Fishman, Z., McRobbie, H., et al. (2007) Smoking and Nurses in New Zealand. ASH-KAN Aotearoa: Assessment of Smoking History, Knowledge and Attitudes of Nurses in New Zealand. ASH, New Zealand.

[5] WHO Tobacco Free Initiative (2010) The Role of Health Professionals in Tobacco Control. World Health Organization, 2005. http://www.paho.org/English/AD/SDE/RA/bookletWNTD05.pdf

[6] Rice, V.H. and Stead, L.F. (2013) Nursing Interventions for Smoking Cessation. Cochrane Database of Systematic Reviews, No. 8, Article ID: CD001188. http://www.thecochranelibrary.com

[7] Sharp, L.T. (2005) Smoking Cessation for Patients with Head and Neck Cancer. Cancer Nursing, 28, 226.

[8] Slama, K. (1998) Tobacco Control and Prevention. A Guide for Low Income Countries. International Union against Tuberculosis and Lung Disease, París. http://www.iuatld.org/pdf/en/guidespublications/tobac coguide.pdf

[9] Alaoui Yazidi, A., Bartal, M., Mahmal, A., et al. (2002) Tabagisme dans les hôpitaux de Casablanca: Connaissances, Attitudes et Pratiques. Revue des Maladies Respiratoires, 19, 435-442.

[10] Beaglehole, R., Epping-Jordan, J., Chopra, M., et al. (2008) Improving the Prevention and Management of Chronic Disease in Low-Income and Middle-Income Countries: A Priority for Primary Health. Lancet, 372, 940-949. http://dx.doi.org/10.1016/S0140-6736(08)61404-X 
[11] Dautzenberg, B. (2004) Tobacco-Related Diseases. La Revue du Praticien, 54, 1877-1882.

[12] Fiore, M.C., Bailey, W.C., Cohen, S.J., et al. (2000) Treating Tobacco Use and Dependence. Clinical Practice Guideline. US Department of Health and Human Services, Rockville. http://www.surgeongeneral.gov/tobacco/treating_tobacco_use.pdf

[13] Raw, M., McNeill, A. and West, R. (1998) Smoking Cessation Guidelines for Health Professionals. A Guide to Effective Smoking Cessation Interventions for the Health Care System. Health Education Authority. Thorax, 53, S1-S19. http://dx.doi.org/10.1136/thx.53.2008.S1

[14] Lancaster, T., Silagy, C. and Fowler, G. (2000) Training Health Professionals in Smoking Cessation. Cochrane Database of Systematic Reviews, 3, Article ID: CD000214.

[15] National Cancer Institute (2009) Cigarette Smoking Prevention. www.enotalone.com/article/7585.html

[16] Pizzo, A.M., Chellini, E., Grazzini, G., et al. (2003) Italian General Practitioners and Smoking Cessation Strategies. Tumori, 89, 250-254.

[17] Nagle, A., Schofield, M. and Redman, S. (1999) Australian Nurses’ Smoking Behaviour, Knowledge and Attitude towards Providing Smoking Cessation Care to Their Patients. Health Promotion International, 14, 133-144. http://dx.doi.org/10.1093/heapro/14.2.133

[18] Toode, K., Routasalo, P. and Suominen, T. (2011) Work Motivation of Nurses: A Literature Review. International Journal of Nursing Studies, 48, 246-257. http://dx.doi.org/10.1016/j.ijnurstu.2010.09.013

[19] Pohkrel, B.R., Thankappan, K.R., Mini, G.K., et al. (2006) Tobacco Use among Health Professionals and Their Role in Tobacco Cessation in Nepal. Prevention and Control, 2, 117-125. http://dx.doi.org/10.1016/j.precon.2007.03.003

[20] Merrill, R.M., Gagon, H., Harmon, T. and Milovic, I. (2010) The Importance of Tobacco Cessation Training for Nurses in Serbia. Journal of Continuing Education in Nursing, 41, 89-96. http://dx.doi.org/10.3928/00220124-20100126-05

[21] Davis, K.C., Nonnomaker, J.M., Farrelly, M.C., et al. (2011) Exploring Differences in Smokers’ Perception of the Effectiveness of Cessation Media Messages. Tobacco Control, 20, 26-33. http://dx.doi.org/10.1136/tc.2009.035568

[22] Sreedharan, J., Muttappallymyalil, J. and Venkatramana, M. (2010) Nurses’ Attitude and Practice in Providing Tobacco Cessation Care to Patients. Journal of Preventive Medicine and Hygiene, 51, 57-61.

[23] Tsung, P. (2002) Nurses Role in Smoking Cessation Knowledge, Attitudes and Behaviors. The University of Hong Kong, Hong Kong. http://hdl.handle.net/10722/28128

[24] Semlali, H. (2010) The Morocco Country Case Study: Positive Practice Environments. Morocco Case Study: Health Care Environments in Morocco. Global Health Workforce Alliance, WHO, Geneva. http://www.who.int/workforcealliance/knowlege/resources/ppemorocco/en/index.html 